\title{
Production of functional probiotic, prebiotic, and synbiotic ice creams
}

\author{
T. Di Criscio, ${ }^{*}$ A. Fratianni, ${ }^{*}$ R. Mignogna, ${ }^{*}$ L. Cinquanta, ${ }^{*}$ R. Coppola, ${ }^{*} \dagger$ E. Sorrentino, ${ }^{*} \dagger$ and G. Panfili ${ }^{* 1}$ \\ ${ }^{*}$ DiSTAAM, Università degli Studi del Molise, Via de Sanctis, 86100 Campobasso, Italy \\ †Istituto di Scienze dell'Alimentazione-CNR, Via Roma, 52 A/C, 83100 Avellino, Italy
}

\section{ABSTRACT}

In this work, 3 types of ice cream were produced: a probiotic ice cream produced by adding potentially probiotic microorganisms such as Lactobacillus casei and Lactobacillus rhamnosus; a prebiotic ice cream produced by adding inulin, a prebiotic substrate; and a synbiotic ice cream produced by adding probiotic microorganisms and inulin in combination. In addition to microbial counts, $\mathrm{pH}$, acidity, and physical and functional properties of the ice creams were evaluated. The experimental ice creams preserved the probiotic bacteria and had counts of viable lactic acid bacteria after frozen storage that met the minimum required to achieve probiotic effects. Moreover, most of the ice creams showed good nutritional and sensory properties, with the best results obtained with $L b$. casei and $2.5 \%$ inulin.

Key words: probiotic, prebiotic, synbiotic, ice cream

\section{INTRODUCTION}

Diet plays an important role in human health. Today, several studies report that the diet can cause or prevent diseases. In recent years, particular attention has been dedicated to the production of functional foods. The main aim of "functional foods" is to introduce microorganisms or beneficial compounds into the organism through daily dietary intake.

A probiotic is a live microbial food supplement that beneficially affects the host animal by improving its intestinal microbial balance. This definition has been broadened to a mono or mixed culture of live microorganism that benefits man or animals by improving the properties of the indigenous microflora (MattilaSandholm et al., 2002; Morelli, 2002; Champagne et al., 2005). Probiotics are viable microorganisms that are beneficial to the host when consumed in appropriate quantities (Heenan et al., 2004). Benefits include inhibition of bacterial pathogens; reduction of serum choles-

Received April 20, 2010

Accepted June 6, 2010.

${ }^{1}$ Corresponding author: panfili@unimol.it terol levels; reduction in the incidence of constipation, diarrhea, and bowel cancer; improvement of lactose tolerance, calcium absorption, and vitamin synthesis; and stimulation of the immune system (Sánchez et al., 2009). For a culture to be considered a valuable candidate for use as a dietary adjunct and to exert a positive influence, it must conform to certain requirements. The culture must be a normal inhabitant of the human intestinal tract, survive passage through the upper digestive tract in large numbers, be capable of filling an ecological niche, and have beneficial effects when in the intestine. To survive, the strain must be resistant to bile salts present in the lower intestine, gastric conditions (pH 1-4), enzymes present in the intestine, and toxic metabolites produced during digestion (Lee and Salminen, 1995; Salminen et al., 1998; Mattila-Sandholm et al., 2002). A concentration of $10^{5} \mathrm{cfu} / \mathrm{g}$ or $\mathrm{mL}$ of the final product has been suggested as the "therapeutic minimum." The consumption of $10^{6}$ to $10^{9}$ viable cells per day is necessary for humans to develop beneficial effects (Lee and Salminen, 1995; Alamprese et al., 2002, 2005). However, when bifidobacteria are the adjunct cultures, the International Dairy Federation suggests that the product should contain at least $10^{7} \mathrm{cfu} / \mathrm{mL}$ of lactic acid bacteria, of which at least $10^{6} \mathrm{cfu} / \mathrm{mL}$ are bifidobacteria (Champagne et al., 2005).

Most of the microorganisms currently used as probiotics belong to a few species of the genera Lactobacillus and Bifidobacterium, but many strains of other species of bacteria and fungi are also used. Lactobacilli are thought to provide several health benefits, including antimicrobial effects against pathogenic bacteria, antitumor effects, and protection against antibioticassociated diarrhea or food allergy. Lactobacilli are reported to be acid and bile tolerant and to survive in the gastrointestinal tract (Desai et al., 2004; Sánchez et al., 2009). Lactobacillus rhamnosus and Lactobacillus casei are thought to be potential probiotics (Collins et al., 1989; Vinderola and Reinheimer, 2003).

A prebiotic was first defined as a nondigestible food ingredient that beneficially affects the host by selectively stimulating the growth or activity of one or a limited number of bacteria in the colon and thus improves host health (Gibson, 2004). Moreover, prebiotics 
can inhibit pathogen multiplication, ensuring additional benefits to host health. Such components mostly act in the large intestine, even though they can also affect microorganisms in the small intestine (MattilaSandholm et al., 2002; Roberfroid, 2002). However, prebiotic characteristics have been attributed to many food components without consideration of the criteria required. In particular, almost every food oligosaccharide and polysaccharide (including dietary fiber) has been claimed to have prebiotic activity, but not all dietary carbohydrates are prebiotic. There is, therefore, a need to establish clear derivatives for classifying a food ingredient as prebiotic. Such classification requires a scientific demonstration that the food component or ingredient resists host digestion, absorption, and adsorption processes, is fermented by the microflora colonizing the gastrointestinal system, and selectively stimulates the growth or the activity of one or a limited number of bacteria within the gastrointestinal system (Gibson, 2004). Recent studies have identified several beneficial attributes of oligofructose and inulin. Inulin and oligofructoses are soluble and fermentable fibers. Inulin is a natural component of several fruits and vegetables and its nutritional properties are well known. It is an indigestible carbohydrate with a reported prebiotic, bifidogenic effect (Roberfroid, 1993, 2002; Langlands et al., 2004). Chemically, native inulin is a fructo-oligosaccharide (FOS), a mixture of oligomer and polymer chains with a variable number of fructose molecules, which usually includes a glucose molecule at the end of the chain. The degree of polymerization of the chains varies between 2 and 60 units with an average of approximately 12 in native inulin (González-Tomás et al., 2009). In most countries, inulin is legally considered a fiber because it acts as a soluble fiber, being digested almost totally in the colon, not in the small intestine (McBain and Macfarlane, 2001). The effects of oligofructose and inulin include management of constipation, improvement of the composition of the intestinal flora by promoting saccharolytic and suppressing proteolytic metabolism with bifidobacteria and lactic acid bacteria as the main indicator organisms, stimulating calcium absorption from food, modulating lipid metabolism, and preventing cancer. Oligofructose and inulin are now recognized as important prebiotic agents influencing the microbiological composition of the gastrointestinal tract and the health of the host (Rao, 2001). Manning and Gibson (2004) indicate that at least $4 \mathrm{~g} / \mathrm{d}$ but preferably $8 \mathrm{~g} / \mathrm{d}$ of FOS would be needed to significantly elevate bifidobacteria in the human gut. Furthermore, based on the results of well-designed human studies that have shown significant changes in the composition of human fecal flora, 5 to $15 \mathrm{~g} / \mathrm{d}$ for a few weeks has a prebiotic effect (Roberfroid, 2002). An inulin intake of
$7.5 \mathrm{~g} / \mathrm{d}$ has been found to be bifidogenic (Langlands et al., 2004).

A further possibility in microflora management procedures is the use of synbiotics, where probiotics and prebiotics can be used in combination. Live microbial additions may be used in conjunction with a specific substrate for growth; for example, FOS with a Bifidobacterium strain or Lactobacillus rhamnosus GG and inulin (Rastall and Maintin, 2002). In synbiotic fermented milks, strains of Lactobacillus acidophilus, Lactobacillus casei, and Bifidobacterium sp. are used as probiotics, whereas FOS, galactooligosaccharides, lactulose, and inulin-derived products are used as prebiotics (Champagne et al., 2005). The result should be improved survival of the probiotic, which has a readily available substrate for its fermentation, as well as the individual advantages that each should offer (Fooks et al., 1999). A boosting combination of probiotics and prebiotics; that is, a synbiotic combination, may result in even better microbial balance in the colon (Roberfroid, 1998; Sairanen et al., 2007). A synbiotic combination of probiotics and inulin has shown promising results by reducing colorectal carcinogenesis in rats (Rowland et al., 1998; Klinder et al., 2004), possibly by modulating the gut-associated lymphoid tissue (Roller et al., 2004). The bifidogenic properties of inulin and other prebiotics are presumed to be the reason for their protective effect against colonic carcinogenesis. There is increasing interest in the abilities of prebiotics and synbiotics to control the symptoms of inflammatory bowel disease (Steed et al., 2008).

Milk and dairy products have been at the forefront in the functional food area and at present, they continue to be the main vehicle for the administration of probiotics and prebiotics through the diet. Different functional dairy products are currently proposed, such as cheeses, yogurts (Lourens-Hattingh and Viljoen, 2001; Dello Staffolo et al., 2004), fermented milks (Salminen et al., 1998; Sánchez et al., 2009), yog-ice creams (ElNagar et al., 2002), cheese-based dips (Tharmaraj and Shah, 2004), probiotic fermented lactic beverages (De Castro et al., 2008), probiotic fiber-enriched fermented milks (De Souza Oliveira et al., 2009), starch-based dairy desserts (González-Tomás et al., 2009), and nonfermented frozen vegetarian desserts (Heenan et al., 2004). In addition, ice cream could be used as a vehicle for delivery of probiotics and prebiotics, if freezing and thawing do not cause damage to the cells and that the final product characteristics are preserved. From the literature data, different papers about probiotic ice creams, produced with different microorganisms are available (Hekmat and McMahon, 1992; Haynes and Playne, 2002; Alamprese et al., 2002, 2005; Turgut and Cakmakci, 2009). 
Table 1. Composition of vanilla and fruit ice creams

\begin{tabular}{lcc}
\hline & \multicolumn{2}{c}{ Amount $(\mathrm{g} / 100 \mathrm{~g})$} \\
\cline { 2 - 3 } Item & $\begin{array}{c}\text { Vanilla } \\
\text { flavor }\end{array}$ & $\begin{array}{c}\text { Fruit } \\
\text { flavor }\end{array}$ \\
\hline Fats & 8.8 & 2.5 \\
Carbohydrates $^{1}$ & 22.2 & 30.2 \\
Milk SNF $^{2}$ & 10.8 & 2.4 \\
Water & 58.2 & 64.9 \\
\hline
\end{tabular}

${ }^{1}$ Sucrose and glucose syrup.

${ }^{2}$ Proteins, lactose, ash of dairy ingredients.

The aim of this study was the production of 1) functional probiotic ice creams by adding strains of Lactobacillus casei and Lactobacillus rhamnosus, 2) prebiotic ice creams, by adding inulin, and 3) synbiotic ice creams, containing the probiotic microorganisms and inulin in combination. The survival of microbial strains during ice cream storage was evaluated. Moreover, the influence of added microorganisms and inulin on chemical, physical, and sensorial characteristics of produced ice creams was studied.

\section{MATERIALS AND METHODS}

\section{Bacterial Strains and Culture Conditions}

The strains used were Lactobacillus rhamnosus DSM 20021 and Lactobacillus casei DSM 20011, purchased from DSMZ collection (Braunschweig, Germany), species considered potential probiotics (Collins et al., 1989; Vinderola and Reinheimer, 2003). For the experiments, the strains were cultured in deMan, Rogosa, and Sharpe (MRS) broth (Oxoid, Basingstoke, UK) at $37^{\circ} \mathrm{C}$ and $28^{\circ} \mathrm{C}$ overnight, respectively. Subsequently, they were inoculated in increasing volumes of skim milk (Oxoid) to achieve $1 \mathrm{~L}$ of inoculated milk that had approximately $10^{9}$ (Lb. rhamnosus) and $10^{8}$ (Lb. casei) cfu $/ \mathrm{mL}$. After incubation at $37^{\circ} \mathrm{C}$ for $L b$. rhamnosus and at $28^{\circ} \mathrm{C}$ for $L b$. casei for $16 \mathrm{~h}$, cells were collected by centrifugation $\left(4,500 \times g\right.$ for $30 \mathrm{~min}$ at $\left.4^{\circ} \mathrm{C}\right)$ and suspended in pasteurized ice cream mix. The occurrence of damage to cells of both strains during frozen storage was evaluated by plate counts in MRS agar supplemented with $1 \%$ bile salts on 16 -wk ice cream samples.

\section{Formulations}

Two different mixes (vanilla and fruit) were formulated for the production of the ice creams. Their composition is shown in Table 1. For the production of probiotic ice creams for each mix, 3 ice creams were produced, 2 with $L b$. rhamnosus or $L b$. casei, respectively, and one without microorganisms as the control.
Samples were identified as follows: fruit control $(\mathbf{F})$; fruit with $L b$. casei $(\mathbf{F c})$; fruit with $L b$. rhamnosus $(\mathbf{F r})$; vanilla control $(\mathbf{V})$; vanilla with $L b$. casei $(\mathbf{V c})$; and vanilla with $L b$. rhamnosus $(\mathbf{V r})$. The stock culture was added during cooling, at $4^{\circ} \mathrm{C}$.

For the production of prebiotic and synbiotic ice creams, the vanilla mix was used. The stabilizer was added at different amounts from 0 to $0.5 \%$. Inulin was added together with the other ingredients after replacing the amount of the stabilizer. Prebiotic ice creams had inulin added as follows: control (plus $0.5 \%$ stabilizer); $2.5 \%$ inulin (plus $0.25 \%$ stabilizer); $5 \%$ inulin; and $10 \%$ inulin.

Synbiotic ice creams contained Lb. casei or Lb. rhamnosus and inulin and were as follows: control (plus $0.5 \%$ stabilizer); $3 \%$ inulin and $L b$. casei; $6 \%$ inulin and $L b$. casei; $3 \%$ inulin and Lb. rhamnosus; and $6 \%$ inulin and Lb. rhamnosus.

\section{Ingredients for Ice Cream Production}

Skim milk powder, sucrose, coconut oil, maltodextrins, cream at $35 \%$, glucose syrup, stabilizer FM 3652 (Degussa Texturant Systems France SAS, Puteaux, France), and vanilla flavor 2786 (DIA SRL, Grumolo delle Abbadesse, Italy) used for both formulations were provided by Gelindo Snc (Campochiaro, Campobasso, Italy), a local ice cream factory. The inulin (Fibruline) was obtained from Cosucra s.a. (Fontenoy, Belgium). The polymer, which is extracted from chicory roots, has a degree of polymerization from 2 to 50 and has an average degree of polymerization of 9 .

\section{Ice Cream Production}

Probiotic ice creams were produced in a local factory, Gelindo Snc, by using the process followed for industrial ice creams. Prebiotic and symbiotic ice creams were produced by using a laboratory plant. The pasteurization was carried out at $85^{\circ} \mathrm{C}$ for $30 \mathrm{~s}$. The probiotic cultures were added after cooling at $15^{\circ} \mathrm{C}$ to reach approximately $10^{7}$ ( Lb. rhamnosus) and $10^{6}$ ( Lb. casei) $\mathrm{cfu} / \mathrm{mL}$. All samples were frozen at $-20^{\circ} \mathrm{C}$ in $250-\mathrm{mL}$ polythene, hinged-lid containers and analyzed after 0 to $1 \mathrm{~d}$, and $1,3,7$, and 16 wk.

\section{Ice Cream Analyses}

Ice creams were analyzed for $\mathrm{pH}$, acidity (Tateo, 1978), total solids (AOAC, 2000; method 941.08), fats (AOAC, 2000; method 952.06), proteins (AOAC, 2000; method 930.33), 12\% TCA-soluble nitrogen (NPN; Resmini et al., 1985), and D/L-lactic acid (Megazyme International, 2004). By means of a dynamometric test 


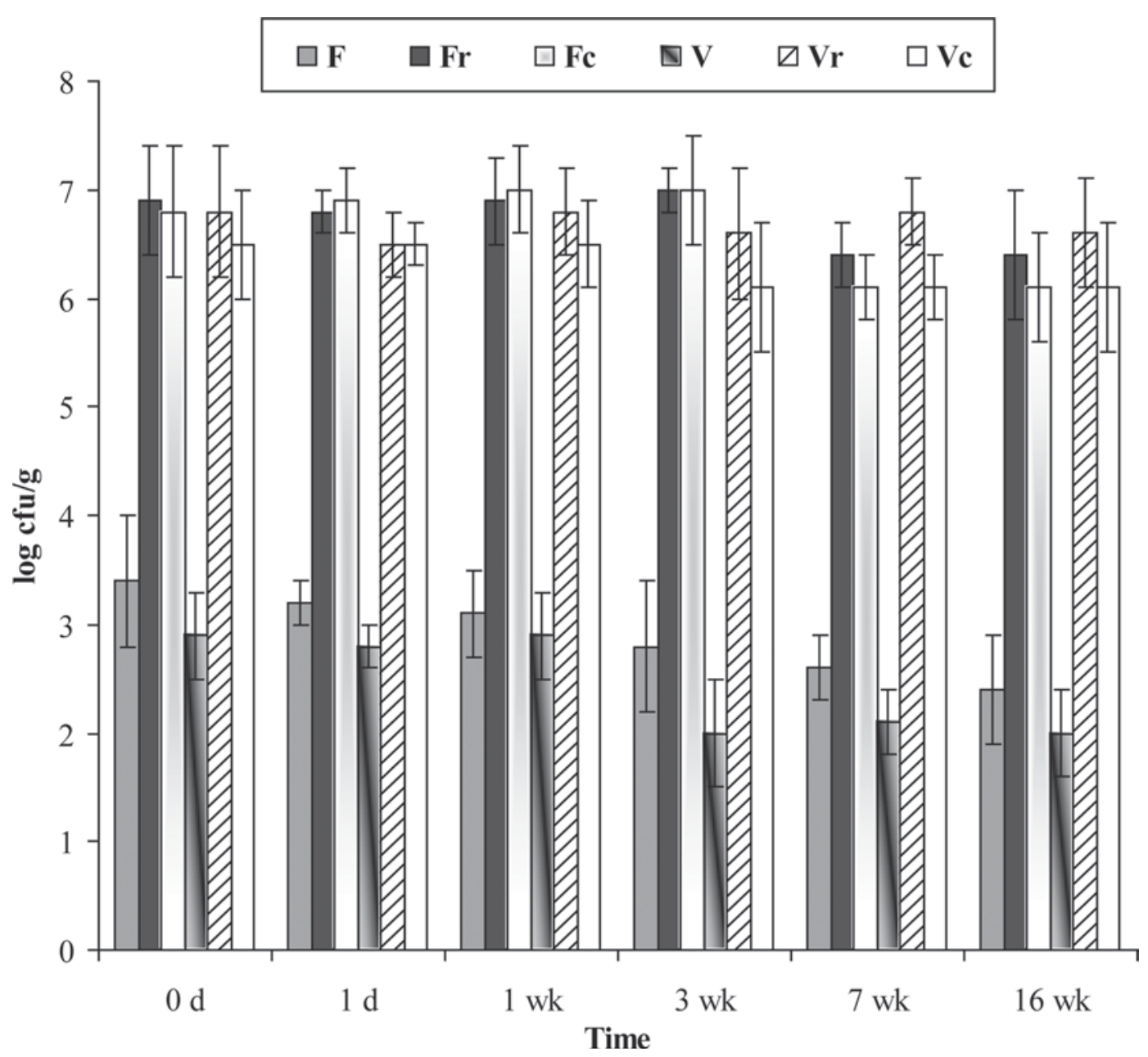

Figure 1. Lactic acid bacteria counts on ice creams after production $(0 \mathrm{~d})$ and during storage. $\mathrm{F}=$ fruit control; Fr $=$ fruit + Lactobacillus rhamnosus $; \mathrm{Fc}=$ fruit + Lactobacillus casei $; \mathrm{V}=$ vanilla control; $\mathrm{Vr}=$ vanilla + Lb. rhamnosus $; \mathrm{Vc}=$ vanilla + Lb. casei.

(dynamometer Ametek Lloyd Instruments LRX plus, Paoli, PA), the analyzed parameters were firmness, expressed as maximum load $(\mathbf{C M})$, in Newton $(\mathrm{N})$, and deformation of maximum load (DML). Ice cream overrun was determined on samples stored at $-20^{\circ} \mathrm{C}$ for $7 \mathrm{~d}$ (Tateo, 1978). Samples (130 g) were placed in a 250-mL graduated cylinder. The cylinder was heated at $50^{\circ} \mathrm{C}$ for $3 \mathrm{~min}$, and $10 \mathrm{~g}$ of isoamylic alcohol was added to remove foam. After cooling, the beaker was made up to volume with distilled water and weighed. After removing the foam from the ice cream, the density of the mix was calculated. The overrun was expressed by the following equation:

$$
\begin{gathered}
\text { Overrun } \%=100 \times(\text { mix density }- \text { ice cream } \\
\text { density }) / \text { ice cream density. }
\end{gathered}
$$

Melting behavior, expressed as melting rate, was evaluated on $70 \pm 5 \mathrm{~mL}$ ice creams stored at $-20^{\circ} \mathrm{C}$ for $7 \mathrm{~d}$. Samples were placed on a wire mesh screen $(4$ meshes) and left to melt into a beaker below the wire mesh screen at room temperature of $24 \pm 2^{\circ} \mathrm{C}$ until $50 \%$ of the sample melted. The weight of the melted ice cream was recorded every $2 \mathrm{~min}$, obtaining a sigmoidal curve representing melting kinetics. From the linear part of the curve, the most probable straight line was calculated, its slope representing the melting rate $(\mathrm{g} / \mathrm{min})$. Results are the average of 3 replicates (ElRahman et al., 1997).

Microbiological analyses were carried out on ice cream samples at $0-1 \mathrm{~d}$, and after $1,3,7$, and $16 \mathrm{wk}$ of frozen storage, according to the following procedure. Ten grams of each ice cream was aseptically transferred into a sterile stomacher bag, diluted with $90 \mathrm{~mL}$ of physiological solution, and homogenized for $1 \mathrm{~min}$ in a Lab-blender 400 stomacher (Seward Laboratory, London, UK). One milliliter of the first dilution was used to obtain 10-fold serial dilutions, which were used for microbial counts. Lactic acid bacteria (LAB) were 

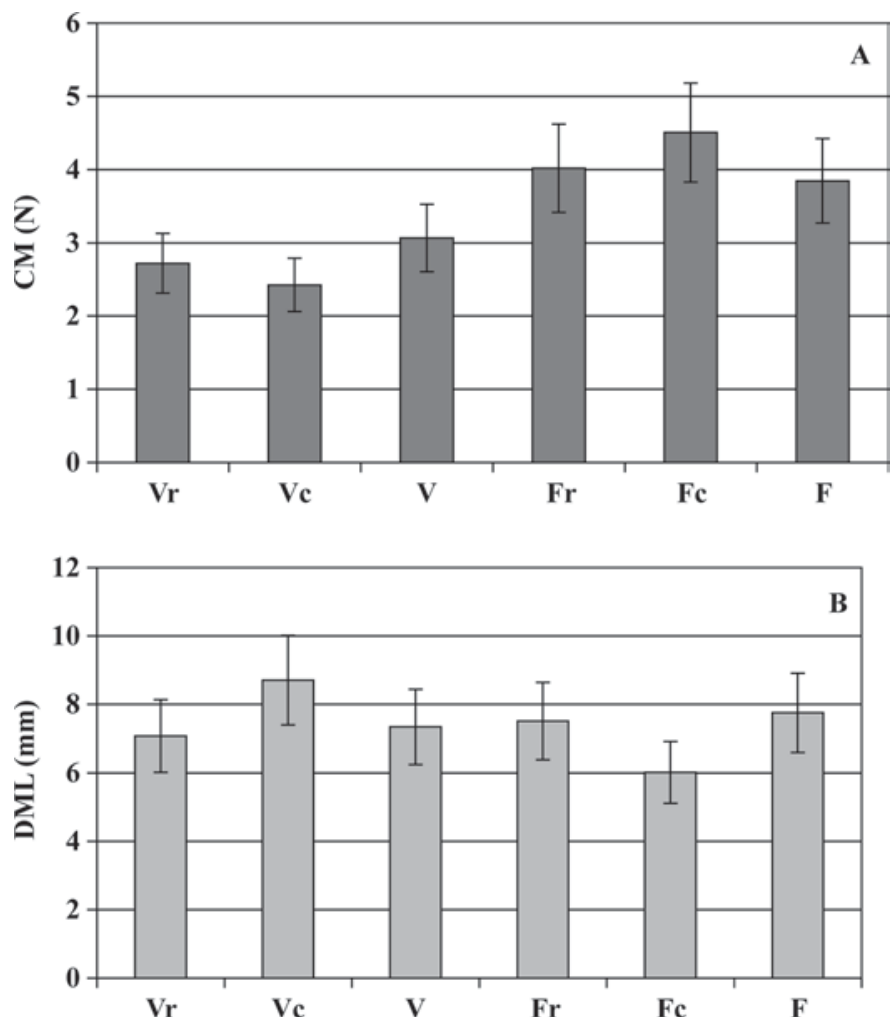

Figure 2. Firmness (CM, A) and deformation maximum load (DML, B) of probiotic ice creams. $\mathrm{F}=$ fruit control; $\mathrm{Fr}=$ fruit + Lactobacillus rhamnosus; $\mathrm{Fc}=$ fruit + Lactobacillus case $; \mathrm{V}=$ vanilla control; $\mathrm{Vr}=$ vanilla $+L b$. rhamnosus; $\mathrm{Vc}=$ vanilla $+L b$. casei.

counted under anaerobiosis on MRS agar (Oxoid) after $48 \mathrm{~h}$ of incubation at $28^{\circ} \mathrm{C}$. Yeasts and molds were quantified on yeast potato dextrose medium (Oxoid) after $72 \mathrm{~h}$ of incubation at $28^{\circ} \mathrm{C}$. Enterobacteriaceae were estimated on violet red bile glucose agar (Oxoid) after $36 \mathrm{~h}$ of incubation at $37^{\circ} \mathrm{C}$. Total and fecal coliforms were counted on violet red bile agar (Oxoid) after 24 to $48 \mathrm{~h}$ of incubation at 37 or $44^{\circ} \mathrm{C}$, respectively.

Sensory assessment was conducted on a semi-trained panel (10 judges) at the University of Molise (Campobasso, Italy) using a checklist proposed by Bollettino Ufficiale Regione Alto Adige (1996). Five terms were used: flavor, homogeneity, color, taste, consistence, with a scale from 1 to 3 for the first 2 terms, from 1 to 4 for consistence, and from 1 to 5 for taste and color. The samples stored at $-20^{\circ} \mathrm{C}$ after $7 \mathrm{~d}$ were removed from the freezer and tempered for 5 min at $20^{\circ} \mathrm{C}$ before sensory analysis.

\section{RESULTS AND DISCUSSION}

\section{Microbiological Analyses of Probiotic Ice Creams}

Undesirable microorganisms (enterobacteria, total and fecal coliforms, and Eumycetes) were detected at very low numbers or not detectable in all probiotic sample ice creams (data not shown). Figure 1 shows results of LAB counts in experimental probiotic ice creams. As expected, counts of several LAB were much higher in probiotic ice cream than in control ice cream samples, at every time point. After production, LAB ranged from 6.5 to $6.9 \mathrm{log} \mathrm{cfu} / \mathrm{g}$ in both formulations of probiotic ice cream samples, whereas LAB counts were less than $3.0 \log \mathrm{cfu} / \mathrm{g}$ in control samples. Moreover, no significant reduction in LAB was observed after freezing and during the storage period, indicating that the storage temperature of $-20^{\circ} \mathrm{C}$ did not negatively affect their survival.

The resistance of probiotic strains to $1 \%$ bile salts was tested after storage at $-20^{\circ} \mathrm{C}$ for $16 \mathrm{wk}$. At $16 \mathrm{wk}$, the counts of LAB able to grow in the presence of $1 \%$ bile salts were about $2.1 \log \mathrm{cfu} / \mathrm{g}$ (Fr and Fc), compared with $2.4 \mathrm{log} \mathrm{cfu} / \mathrm{g}$ of the respective control sample growth on MRS, and $1.5 \log \mathrm{cfu} / \mathrm{g}(\mathrm{Vr})$ and $1.9 \mathrm{log} \mathrm{cfu} / \mathrm{g}(\mathrm{Vc})$, compared with $2.0 \mathrm{log} \mathrm{cfu} / \mathrm{g}$ of the control ice cream on MRS. These results show that bile resistance depends on strains and on ice cream composition.

\section{Chemical and Physical Analyses of Probiotic Ice Creams}

Ice creams were characterized to assess the most common quality indexes. In products with added microorganisms, no significant variations of composition were shown. Results showed that acidity did not change during storage, in either control or probiotic ice creams (data not shown).

Inoculated fruit ice creams showed higher firmness (higher CM) than vanilla ice creams because of the lower fat and higher sugar that influence the hardening process and storage (Alamprese et al., 2002; Figure 2A). In probiotic ice creams, functional properties (CM and DML) were not significantly influenced by the presence of microorganisms (Figure 2A and 2B; $P>0.05$ ).

\section{Sensory Assessment of Probiotic Ice Creams}

Sensory attributes of the probiotic ice creams are profiled in Figure 3. Base fruit ice creams (F) were perceived more negatively compared with vanilla ice cream samples (V), probably because of the total absence of flavors and the lower fat content. The most appreciated vanilla ice cream was the one with added $L b$. casei (Vc), compared with ice cream with Lb. rhamnosus $(\mathrm{Vr})$ and the control ice cream. Probiotic vanilla ice cream was only slightly lower in taste intensity compared with the control ice cream.

\section{Physical Analyses of Prebiotic Ice Creams}

Not surprisingly, the functional characteristics of prebiotic ice creams (overrun, firmness, and melting 


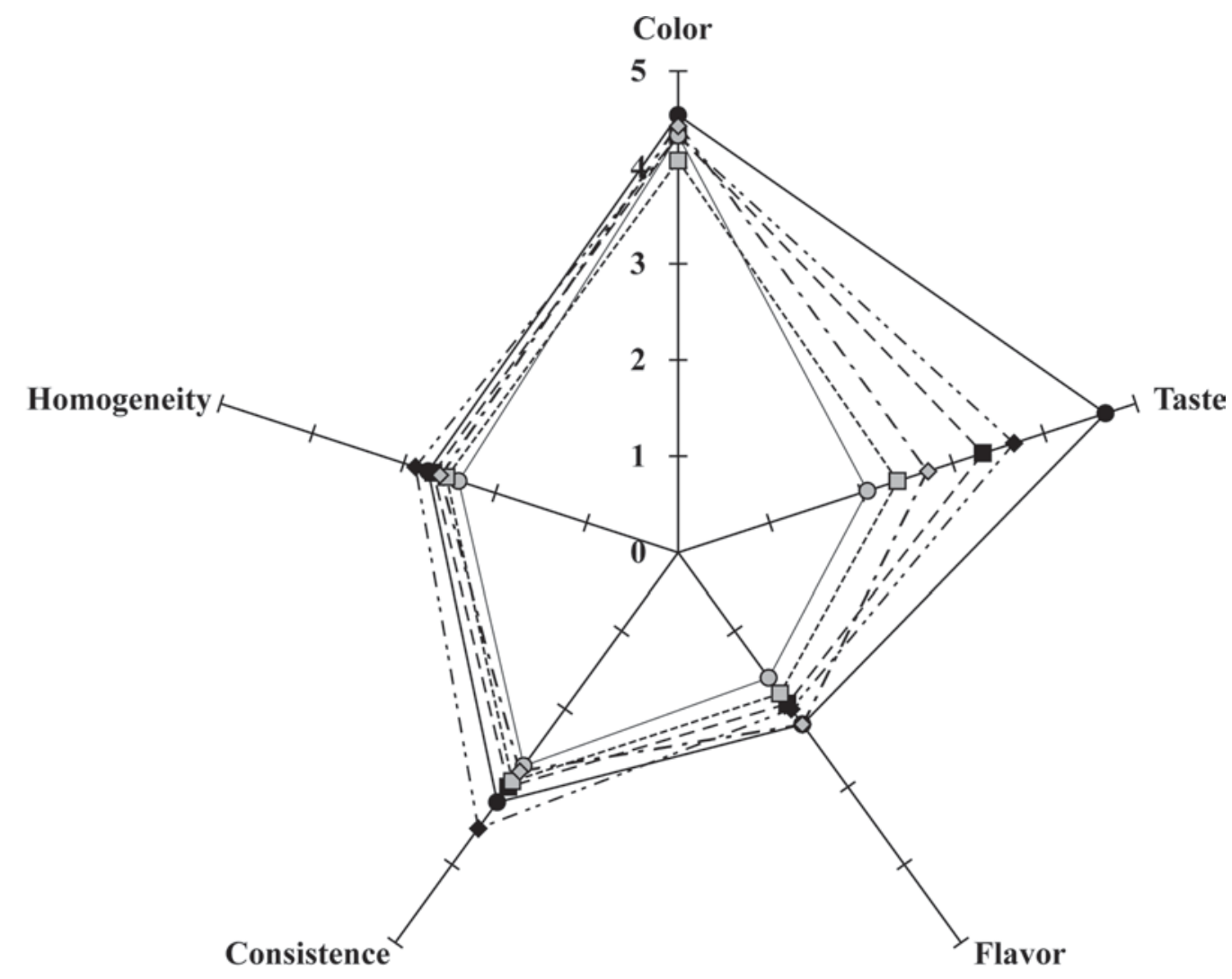

\begin{tabular}{lllllll|}
\hline$\longrightarrow--V r$ & $-\bullet-V c$ & $0-F$ & $---\square--F r$ & $-\diamond \cdot F c$ \\
\hline
\end{tabular}

Figure 3. Graphical representation of sensory evaluation of probiotic ice creams. $\mathrm{F}=$ fruit control; Fr $=$ fruit + Lactobacillus rhamnosus; Fc $=$ fruit + Lactobacillus case $; \mathrm{V}=$ vanilla control $; \mathrm{Vr}=$ vanilla + Lb. rhamnosus $; \mathrm{Vc}=$ vanilla + Lb. casei.

rate) were influenced by the percentage of added inulin. Table 2 shows the results of physical analysis of prebiotic ice creams as an average of 5 determinations. The addition of inulin altered the texture of the ice creams. In particular, in ice creams with 5 and $10 \%$ inulin, the overall firmness $(\mathrm{CM})$ and DML significantly increased by about 50 and $25 \%$, respectively $(P<0.05)$. This behavior could be related to changes in freezing points because of higher solute concentrations together with the gelling properties of inulin and the increased water binding, which improve viscosity and modify the rheology of the mix (El-Nagar et al., 2002). The prebiotic ice cream with the best firmness characteristic was that with $2.5 \%$ inulin, for which no significant differences were found compared with the control ice cream.

All prebiotic ice creams showed overrun values similar to those found in literature for artisanal ice creams (40-50\%). In comparison, ice creams with inulin added at 5 and $10 \%$ had overrun values about $15 \%$ lower (Table 2).
Melting rate values ranged from 1.98 to $2.50 \mathrm{~g} / \mathrm{min}$ (Table 2), in agreement with literature data (Alamprese et al., 2002; Muse and Hartel, 2004). No significant differences were found between control samples and samples with $2.5 \%$ inulin, probably because of the presence of the stabilizer. Samples with $5 \%$ inulin had a significantly higher melting rate compared with control and $2.5 \%$ inulin samples $(P<0.05)$; these values tended to stabilize with $10 \%$ inulin. Literature data on yog-ice cream showed that the addition of $5 \%$ inulin significantly increases the rate of meltdown, which decreases from 5 to $9 \%$ because of the formation of a cohesive network able to bind water, thus reducing the mobility of water molecules among other molecules of the mix (El-Nagar et al., 2002).

\section{Sensory Assessment of Prebiotic Ice Creams}

Sensory attributes of the prebiotic ice creams are profiled in Figure 4. Addition of $10 \%$ inulin lowered the 
Table 2. Physical analyses performed on prebiotic ice creams stored at $-20^{\circ} \mathrm{C}$ (means $\pm \mathrm{SD}$ )

\begin{tabular}{lcccc}
\hline Sample $^{1}$ & $\begin{array}{c}\text { Overrun } \\
(\%)\end{array}$ & $\begin{array}{c}\text { Firmness } \\
(\mathrm{N})\end{array}$ & $\begin{array}{c}\text { Deformation } \\
\text { maximum load }(\mathrm{mm})\end{array}$ & $\begin{array}{c}\text { Melting rate } \\
(\mathrm{g} / \mathrm{min})\end{array}$ \\
\hline $\mathrm{I}$ & $37.0 \pm 0.5$ & $2.83 \pm 0.37$ & $8.43 \pm 0.44$ & $2.14 \pm 0.05$ \\
$\mathrm{I}_{2.5}$ & $37.2 \pm 1.3$ & $2.28 \pm 0.26$ & $9.10 \pm 1.03$ & $1.98 \pm 0.10$ \\
$\mathrm{I}_{5}$ & $38.8 \pm 0.3$ & $4.33 \pm 0.27$ & $10.70 \pm 0.48$ & $2.50 \pm 0.08$ \\
$\mathrm{I}_{10}$ & $38.4 \pm 0.5$ & $4.13 \pm 0.12$ & $10.30 \pm 0.33$ & $2.34 \pm 0.10$ \\
\hline
\end{tabular}

${ }^{1} \mathrm{I}=$ control; $\mathrm{I}_{2.5}=2.5 \%$ inulin; $\mathrm{I}_{5}=5 \%$ inulin; $\mathrm{I}_{10}=10 \%$ inulin.

sensory characteristics of ice creams mainly for taste and flavor, but also for consistency and homogeneity. These results are consistent with physical analyses of Table 2. The best ice cream was that with $2.5 \%$ inulin, showing values similar to the control ice cream, for all tested parameters.

\section{Microbiological Analyses of Synbiotic Ice Creams}

Similar to results reported for probiotic ice creams, undesirable microorganisms were found at very low or nondetectable levels in the synbiotic ice creams (data not shown). Figure 5 shows the results of LAB counts in synbiotic ice creams. In synbiotic ice creams at $0 \mathrm{~d}$, LAB ranged from 6.5 to $6.9 \mathrm{log} \mathrm{cfu} / \mathrm{g}$ in all samples and were higher than in control samples during storage. In control samples, LAB counts reached $2.5 \mathrm{log} \mathrm{cfu} / \mathrm{g}$ after production and were approximately the same at 16 wk.

After freezing and during the storage period, a slight but not significant reduction in the number of LAB was
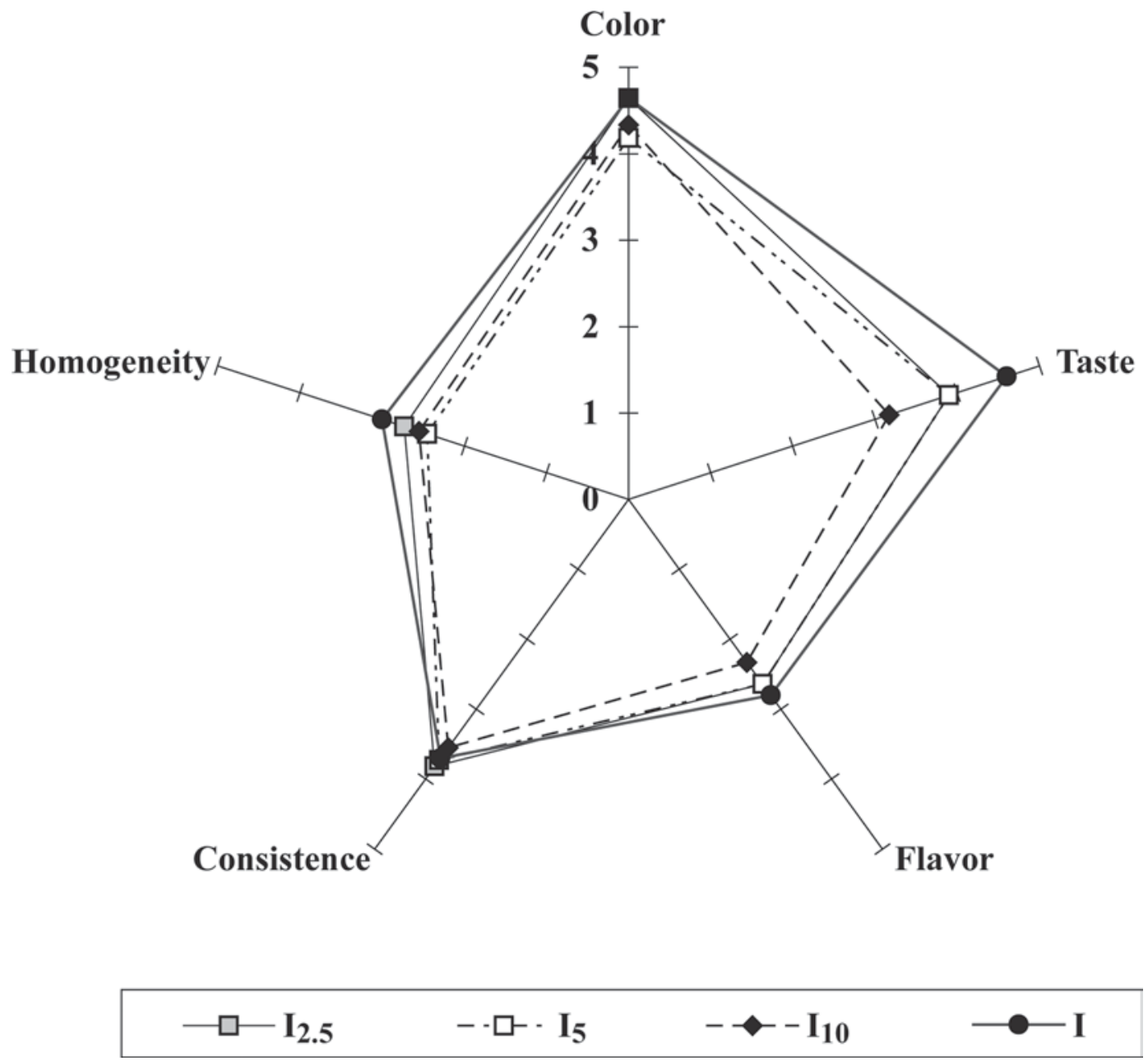

Figure 4. Graphical representation of sensory evaluation of prebiotic ice creams. $\mathrm{I}_{2.5}=2.5 \%$ inulin; $\mathrm{I}_{5}=5 \%$ inulin; $\mathrm{I}_{10}=10 \%$ inulin; $\mathrm{I}=$ control. 


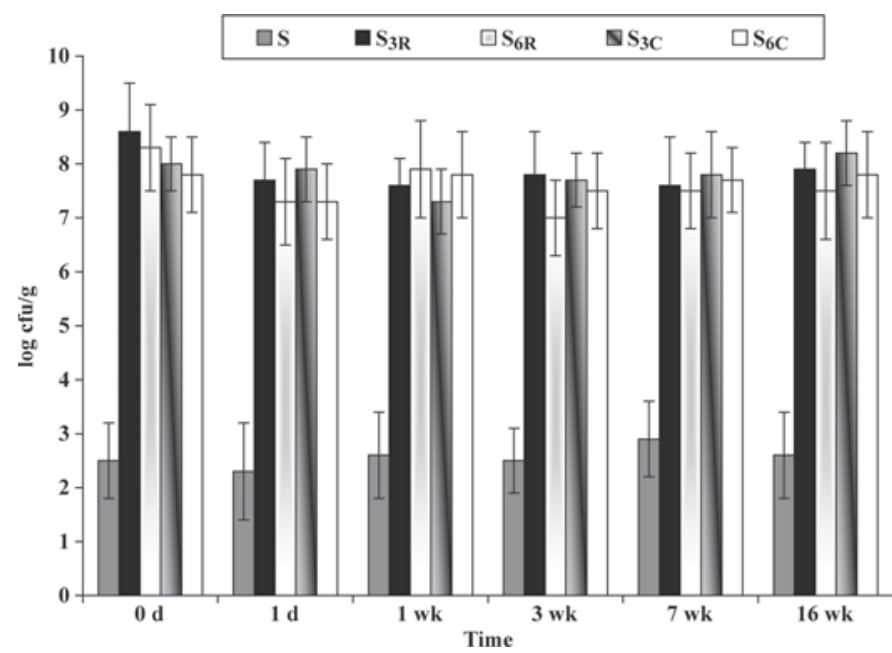

Figure 5. Lactic acid bacteria counts on synbiotic ice creams after production $(0 \mathrm{~d})$ and during storage. $\mathrm{S}=$ control; $\mathrm{S}_{3 \mathrm{R}}=3 \%$ inulin + Lactobacillus rhamnosus; $\mathrm{S}_{6 \mathrm{R}}=6 \%$ inulin + Lb. rhamnosus; $\mathrm{S}_{3 \mathrm{C}}=3 \%$ inulin + Lactobacillus casei; $\mathrm{S}_{6 \mathrm{C}}=6 \%$ inulin + Lb. casei.

observed, showing that freezing temperatures do not negatively affect survival of LAB. Moreover, the LAB counts did not seem to be affected by the presence of inulin.

The resistance of probiotic strains to $1 \%$ bile salts was tested after storage for $16 \mathrm{wk}$ at $-20^{\circ} \mathrm{C}$. At $16 \mathrm{wk}$, the counts of $L b$. rhamnosus able to grow in presence of $1 \%$ bile salts, compared with counts in MRS (2.6 log $\mathrm{cfu} / \mathrm{g})$, were about $2.1 \mathrm{log} \mathrm{cfu} / \mathrm{g}$. In contrast, at the same time, the counts of $L b$. casei able to growth in presence of $1 \%$ bile salts, compared with MRS counts, were about $2.0 \log \mathrm{cfu} / \mathrm{g}$.

\section{Chemical and Physical Analyses of Synbiotic Ice Creams}

In synbiotic samples, significant variations of centesimal composition were not found. Results showed the absence of proteolytic activity after production and during storage. The acidity values did not change during freezing storage in control and synbiotic ice creams (data not shown).
Table 3 shows the results of physical analysis on synbiotic ice creams, as an average of 9 determinations. The addition of inulin did not significantly affect the texture of $3 \%$ inulin ice creams, whereas overall firmness (CM) increased by about 20 to $30 \%$ in $6 \%$ inulin ice creams $(P<0.05)$. No significant differences were observed for DML values. All synbiotic ice cream formulations showed overrun values similar to those found in literature for artisanal ice creams (40-50\%), with no significant decrease compared with control ice creams $(P>0.05)$.

\section{Sensory Assessment of Synbiotic Ice Creams}

Sensory attributes of the synbiotic ice creams are profiled in Figure 6. Addition of microorganisms and inulin did not significantly affect ice creams for consistency, taste intensity, or homogeneity. Poor results were observed for color, which appeared more opaque, whereas better evaluations were expressed for flavor, because of a higher sweetness intensity. Ice creams with $6 \%$ inulin were less icy compared with those with $3 \%$ inulin. These results are in accordance with Schaller-Povolny and Smith (1999), who observed a cryoprotectant effect of inulin that helps in reduction of ice crystal growth. The best ice cream was that with $L b$. rhamnosus and $6 \%$ inulin, followed by ice cream with $L b$. casei and $6 \%$ inulin.

\section{CONCLUSIONS}

Nutritional benefits associated with soluble dietary fiber, probiotic microorganisms, or both, could bring attractive novel products to fulfill market niches. Strains of $L b$. casei and Lb. rhamnosus showed high survival at the end of production and good survival during frozen storage, maintaining counts of $10^{6}$ to $10^{7} \mathrm{cfu} / \mathrm{g}$, even in the presence of inulin. Therefore, with a standard ice cream dietary intake (about $80 \mathrm{~g}$ ), it is possible to obtain at least $10^{7}$ viable cells/d, which is necessary to achieve temporary intestinal colonization. High inulin doses $(10 \%)$ altered the sensorial and physical properties of prebiotic ice creams. Using formulations with $2.5 \%$ inulin (which did not adversely affect ice cream charac-

Table 3. Physical analyses performed on synbiotic ice creams stored at $-20^{\circ} \mathrm{C}$ (means and SD)

\begin{tabular}{|c|c|c|c|}
\hline Sample $^{1}$ & $\begin{array}{l}\text { Firmness } \\
(\mathrm{N})\end{array}$ & $\begin{array}{c}\text { Deformation } \\
\text { maximum load }(\mathrm{mm})\end{array}$ & $\begin{array}{l}\text { Overrun } \\
\quad(\%)\end{array}$ \\
\hline $\mathrm{S}$ & $5.31 \pm 0.24$ & $5.79 \pm 0.27$ & $43.2 \pm 1.72$ \\
\hline $\mathrm{S}_{3 \mathrm{C}}$ & $5.02 \pm 0.53$ & $6.28 \pm 0.82$ & $43.3 \pm 2.22$ \\
\hline $\mathrm{S}_{6 \mathrm{C}}$ & $6.30 \pm 0.15$ & $6.96 \pm 0.55$ & $42.6 \pm 1.32$ \\
\hline $\mathrm{S}_{3 \mathrm{R}}$ & $4.60 \pm 0.48$ & $6.08 \pm 0.69$ & $42.7 \pm 2.72$ \\
\hline $\mathrm{S}_{6 \mathrm{R}}$ & $6.86 \pm 0.22$ & $5.06 \pm 0.74$ & $41.6 \pm 1.82$ \\
\hline
\end{tabular}




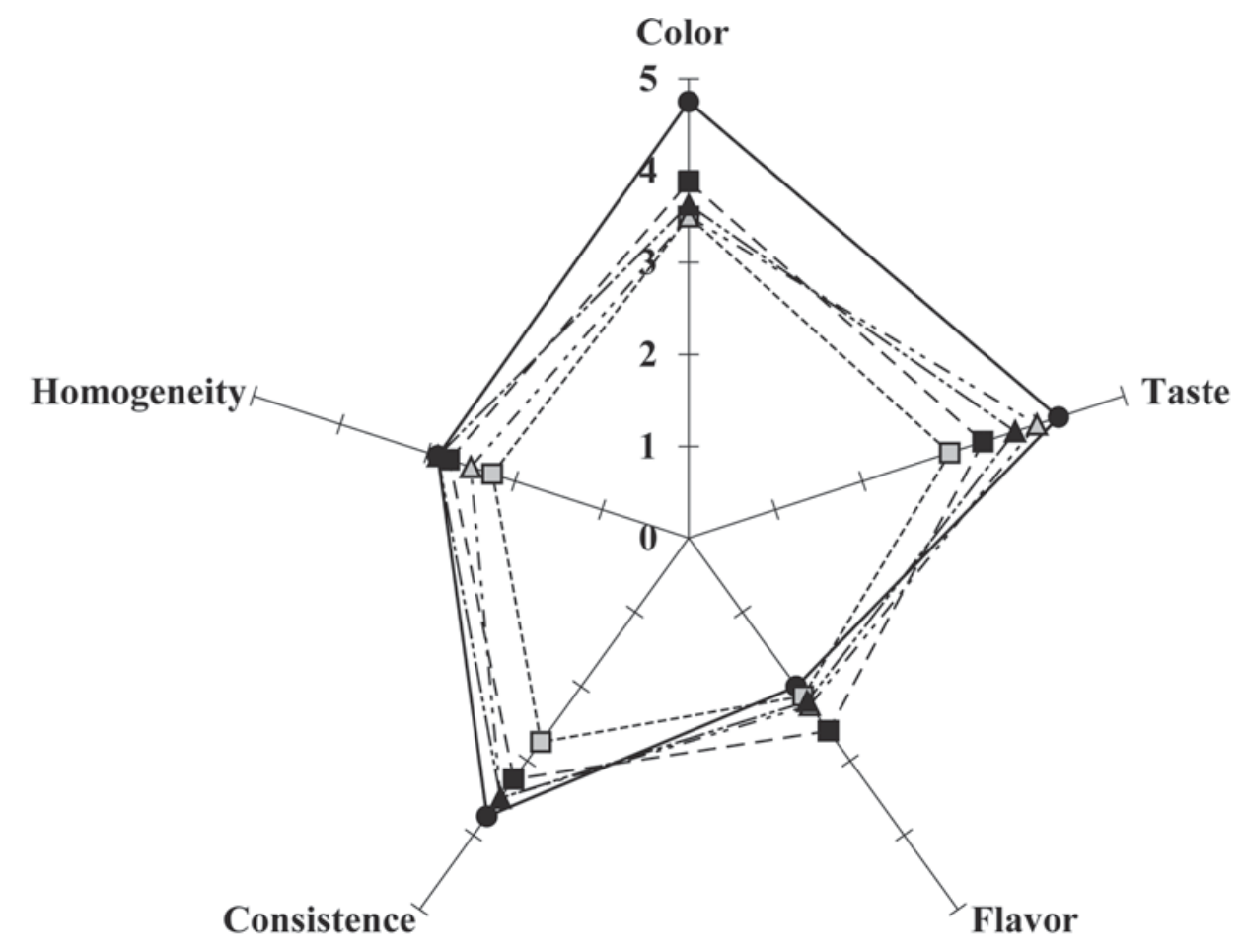

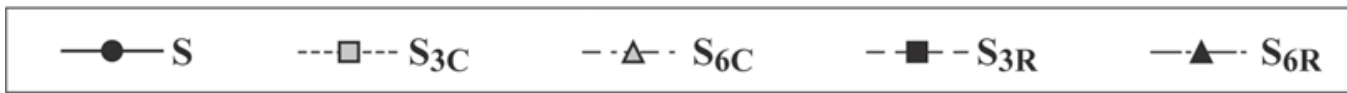

Figure 6. Graphical representation of sensory evaluation of synbiotic ice creams. $\mathrm{S}=$ control; $\mathrm{S}_{3 \mathrm{R}}=3 \%$ inulin + Lactobacillus rhamnosus; $\mathrm{S}_{6 \mathrm{R}}=6 \%$ inulin + Lb. rhamnosus; $\mathrm{S}_{3 \mathrm{C}}=3 \%$ inulin + Lactobacillus casei; $\mathrm{S}_{6 \mathrm{C}}=6 \%$ inulin + Lb. casei.

teristics), it is possible to cover the $40 \%$ intake (about $5 \mathrm{~g} / \mathrm{d}$, assuming intake of $80 \mathrm{~g}$ of ice cream) needed for beneficial effects on intestinal microorganisms. Finally, it should be possible to produce a functional ice cream (synbiotic) with inulin (minimum 3\%) and potentially probiotic microorganisms. In vivo investigation of the effects of synbiotic ice creams would be worthwhile.

\section{ACKNOWLEDGMENTS}

The authors thank Gelindo Snc (Campochiaro, Campobasso, Italy) for the production of probiotic and prebiotic ice creams.

\section{REFERENCES}

Alamprese, C., R. Foschino, M. Rossi, C. Pompei, and S. Corti. 2005. Effects of Lactobacillus rhamnosus GG addition in ice cream. Int. J. Dairy Technol. 58:200-206.

Alamprese, C., R. Foschino, M. Rossi, C. Pompei, and L. Savani. 2002. Survival of Lactobacillus johnsonii La1 and influence of its addition in retail-manufactured ice cream produced with different sugar and fat concentrations. Int. Dairy J. 12:201-208.

AOAC. 2000 Official Methods of Analysis. Vol. II. 17th ed. Association of Official Analytical Chemists, Arlington, VA.
Bollettino Ufficiale Regione Alto Adige. 1996. Nuovo regolamento per il settore latte e latticini dell'Alto Adige. Bollettino Ufficiale Regione Alto Adige, n 24/21 Maggio 1996. Ufficio del Bollettino Ufficiale, Trento, Italy.

Champagne, C. P., N. J. Gardner, and D. Roy. 2005. Challenges in the addition of probiotic cultures to foods. Crit. Rev. Food Sci. Nutr. 45:61-84.

Collins, M. D., B. A. Phillips, and P. Zanoni. 1989. Deoxyribonucleic acid homology studies of Lactobacillus casei, Lactobacillus paracasei sp. nov., ssp. paracasei and ssp. tollerans and Lactobacillus rhamnosus sp. nov., comb. nov. J. Syst. Bacteriol. 39:105-108.

De Castro, F. P., T. M. Cunha, P. L. M. Barreto, R. D. D. E. M. C. Amboni, and E. S. Prudêncio. 2008. Effect of oligofructose incorporation on the properties of fermented probiotic lactic beverages. Int. J. Dairy Technol. 62:68-74.

De Souza Oliveira, R. P., P. Perego, A. Converti, and M. N. De Oliveira. 2009. The effect of inulin as a prebiotic on the production of probiotic fibre-enriched fermented milk. Int. J. Dairy Technol. 62:195-203.

Dello Staffolo, M., N. Bertola, M. Martino, and Y. A. Bevilacqua. 2004. Influence of dietary fiber addition on sensory and rheological properties of yogurt. Int. Dairy J. 14:263-268.

Desai, A. R., I. B. Powell, and N. P. Shah. 2004. Survival and activity of probiotic lactobacilli in skim milk containing prebiotics. J. Food Sci. 69:FMS57-FMS60.

El-Nagar, G., G. Clowes, C. M. Tudoricã, V. Kuri, and C. S. Brennan. 2002. Rheological quality and stability of yog-ice cream with added inulin. Int. J. Dairy Technol. 55:89-93.

El-Rahman, A., S. Madkor, F. Ibrahim, and A. Kilara. 1997. Physical characteristics of frozen desserts made with cream, anhydrous milk fat, or milk fat fractions. J. Dairy Sci. 80:1926-1935. 
Fooks, L. J., R. Fuller, and G. R. Gibson. 1999. Prebiotics, probiotics and human gut microbiology. Int. Dairy J. 9:53-61.

Gibson, G. R. 2004. Fibre and effects on probiotics (the prebiotic concept). Clin. Nutr. Suppl. 1:25-31.

González-Tomás, L., S. Bayarri, and E. Costell. 2009. Inulin-enriched dairy desserts: Physicochemical and sensory aspects. J. Dairy Sci. 92:4188-4199.

Haynes, I. N., and M. J. Playne. 2002. Survival of probiotic cultures in low-fat ice cream. Aust. J. Dairy Technol. 57:10-14.

Heenan, C. N., M. C. Adams, R. W. Hosken, and G. H. Fleet. 2004 Survival and sensory acceptability of probiotic microorganisms in a nonfermented frozen vegetarian dessert. Lebensm. Wiss. Technol. 37:461-466.

Hekmat, S., and D. J. McMahon. 1992. Survival of Lactobacillus acidophilus and Bifidobacterium bifid in ice cream for use as probiotic food. J. Dairy Sci. 75:1415-1422.

Klinder, A., A. Forster, G. Cardeni, A. P. Fermia, and B. L. PoolZobel. 2004. Fecal water genotoxicity is predictive of tumor-preventive activities by inulin-like oligofructoses, probiotics (Lactobacillus rhamnosus and Bifidobacterium lactis), and their symbiotic combination. Nutr. Cancer 49:144-155.

Langlands, S. J., M. J. Hopkins, N. Coleman, and J. H. Cummings, 2004. Prebiotics carbohydrates modify the mucosa associated microflora of the human large bowel. Gut 53:1610-1616.

Lee, Y. K., and S. Salminen. 1995. The coming of age of probiotics. Trends Food Sci. Technol. 6:241-245.

Lourens-Hattingh, A., and B. C. Viljoen. 2001. Yogurt as probiotic carrier food. Int. Dairy J. 11:1-17.

Manning, T. S., and G. R. Gibson. 2004. Prebiotics. Best Pract. Res. Clin. Gastroenterol. 18:287-298.

Mattila-Sandholm, T., P. Myllärinen, R. Crittenden, G. Mongesen, R Fondén, and M. Saarela. 2002. Technological challenger for future probiotic foods. Int. Dairy J. 12:173-182.

McBain, A. J., and G. T. Macfarlane. 2001. Modulation of genotoxic enzyme activities by non-digestible oligosaccharide metabolism in in vitro human gut bacterial ecosystems. J. Med. Microbiol. $50: 833-842$.

Megazyme International. 2004. Assay procedures. K-DLATE 01/05. Megazyme International Bray, Co. Wicklow, Ireland.

Morelli, L. 2002. Probiotics: Clinics and/or nutrition. Dig. Liver Dis. 34(Suppl. 2):S8-S11.

Muse, M. R., and R. W. Hartel. 2004. Ice cream structural elements that affect melting rate and hardness. J. Dairy Sci. 87:1-10.

Rao, V. A. 2001. The probiotic properties of oligofructose at low intake levels. Nutr. Res. 21:843-848.

Rastall, R. A., and V. Maintin. 2002. Prebiotics and synbiotics: Towards the next generation. Curr. Opin. Biotechnol. 13:490-496.

Resmini, P., C. Tripiciano, M. Rampilli, and R. Lodi. 1985. Alcuni aspetti del controllo qualità del latte al consumo. Riv. Soc. It. Sci. Alim. 3:187-196.
Roberfroid, M. 1993. Dietary fiber, inulin, oligofructose: A review comparing their physiological effects. Crit. Rev. Food Sci. Nutr. $33: 103-148$.

Roberfroid, M. B. 1998. Prebiotics and synbiotics: Concepts and nutritional properties. Br. J. Nutr. 80:S197-S202.

Roberfroid, M. 2002. Functional food concept and its application to prebiotics. Dig. Liver Dis. 34(Suppl. 2):S105-S110.

Roller, M., A. Pietro Fermia, G. Caderni, G. Rechkemmer, and B. Watzl. 2004. Intestinal immunity of rats with colon cancer is modulated by oligofructose-enriched inulin combined with Lactobacillus rhamnosus and Bifidobacterium lactis. Br. J. Nutr. 92:931-938.

Rowland, I. R., C. J. Rumney, J. T. Coutts, and L. C. Lievense. 1998. Effect of Bifidobacterium longum and inulin on gut bacterial metabolism and carcinogen-induced aberrant crypt foci in rats. Carcinogenesis 19:281-285.

Sairanen, U., L. Piirainen, S. Gråsten, T. Tompuri, J. Mättö, M. Saarela, and R. Korpela. 2007. The effect of probiotic fermented milk and inulin on the functions and microecology of the intestine. J. Dairy Res. 74:367-373.

Salminen, S., A. von Wright, L. Morelli, P. Marteau, D. Brassart, W. M. de Vos, R. Fondén, M. Saxelin, K. Collins, G. Mogensen, S. E. Birkeland, and T. Mattila-Sandholm. 1998. Demonstration of safety of probiotics - A review. Int. J. Food Microbiol. 44:93-106.

Sánchez, B., C. G. De Los Reyes-Gavilán, A. Margolles, and M. Gueimonde. 2009. Probiotic fermented milks: Present and future. Int. J. Dairy Technol. 62:472-483.

Schaller-Povolny, L. A., and D. E. Smith. 1999. Sensory attributes and storage life of reduced fat ice cream as related to inulin content. J. Food Sci. 64:555-559.

Steed, H., G. T. Macfarlane, and S. Macfarlane. 2008. Prebiotics, synbiotics and inflammatory bowel disease. Mol. Nutr. Food Res. 52:898-905.

Tateo, F. 1978. Gelati. Pages 307-322 in Analisi dei Prodotti Alimentari. Vol. 2. Chiriotti Editori, Pinerolo, Torino, Italy.

Tharmaraj, N., and N. P. Shah. 2004. Survival of Lactobacillus acidophilus, Lactobacillus paracasei ssp. paracasei, Lactobacillus rhamnosus, Bifidobacterium animalis and Propionibacterium in cheesebased dips and the suitability of dips as effective carriers of probiotic bacteria. Int. Dairy J. 14:1055-1066.

Turgut, T., and S. Cakmakci. 2009. Investigation of the possible use of probiotics in ice cream manufacture. Int. J. Dairy Technol. 62:444-451.

Vinderola, C. G., and J. A. Reinheimer. 2003. Lactic acid starter and probiotic bacteria: A comparative "in vitro" study of probiotic characteristics and biological barrier resistance. Food Res. Int. $36: 895-904$. 